\title{
THE SPRUCE BUDWORM IN BRITISH COLUMBIA
}

\author{
By W. G. Mathers \\ Dominion Entomological Laboratory, Vernon, B.C.
}

$\mathrm{T}$

HE spruce budworm, Cacoecia fumiferana Clem., is distributed generally throughout British Columbia and undoubtedly occurs throughout the range of the Douglas fir and the balsam firs in Western North America. In the West it has been recorded from as far south as New Mexico and north to the central interior of British Columbia, and from the continental divide west to the Pacific coast.

The first recorded infestation in Western Canada occurred in 1909 on the south-eastern portion of Vancouver Island. Since that time outbreaks have been constantly reported in British Columbia, and during the past few years the writer was given the opportunity to study outbreaks occurring on Vancouver Island and also in the Barkerville district in the central interior of the province.

The preferred hosts in British Columbia have been Douglas fir, Pseudot. suga taxifolia (LaMarck) Britt., particularly the dry belt form, and alpine fir or balsam, Abies lasiocarpa (Hook) Nutt. The infestations have occurred in stands in which one of the preferred hosts predominated and which consisted generally of mature trees of low vitality. Secondary species such as lowland fir, Abies grandis Lind., associated with Douglas fr, and Engelmann spruce, Picea engelmanni Engel., with alpine fir, have also been fed upon to a considerable extent. In addition larvae were also found feeding on lodgepole pine, Pinus contorta Loud, but this species was by no means a preferred host.

The spruce budworm as found in British Columbia cannot be separated taxonomically from the eastern form. Also the general habits and life-history of the two forms for the most part are practically identical. The young overwintering caterpillars emerge from the overwintering hibernacula in the spring, coincident with or a few days before the opening of the buds of the host trees. The larvae immediately commence to feed either directly on the new growth, if such is present, or by mining into the unopened buds. The duration of the feeding period is influenced to a considerable extent by climatic conditions and under average conditions may vary from 30 to 40 days. On becoming fully developed the caterpillars pupate within a loose silken shelter spun among the foliage. The pupal period varies from 12 to 18 days, and the moths are on the wing in July or August, depending on the locality. Egg laying takes place soon after the moths emerge and the flight period extends over a period of about two weeks. The eggs are laid in masses either on the upper or underside of the needles, and hatch within 9 to 12 days. On hatching the young caterpillar seeks a sheltered nook such as between bud scales, 
under lichen, or at the base of twigs where it spins a hibernaculum in which it remains until the following spring. The hibernacula are usually completed within 2 to 5 days from the time the larvae emerge from the eggs.

The newly emerged larvae in the spring are pale yellow with a blackishbrown head and a pale brown thoracic shield, while the mature larvae which are about one inch in length are dark brown or reddish-brown with dark brown or black head and thoracic shield. The pupae are about one half inch in length, moderately slender and tapering, and dark reddish brown in colour, with transverse bands and spots of black brown. The moths are close to one half inch in length and have a wing spread of from three quarters of an inch to one inch. The fore wings are somewhat oblong in shape and very variable in markings and colour. The ground colour may vary from grey to a reddish brown and is overlaid with bands, streaks and spots of brown or rust red. However, there is usually a rather large conspicuous whitish spot in the middle of the upper margin of the fore wing.

Although the life cycle of the spruce budworm, as outlined above, is normally completed in one year, the studies of the Barkerville infestation showed that, during the past three years at least, the budworm required two years to complete its life cycle in that locality.

In the Barkerville district in 1929 the first feeding by the young overwintering larvae occurred about the middle of June. During the following month the development of the caterpillars was so retarded as a direct result of unfavourable weather conditions, that the average length of the larvae at the end of this period was still not over $5.5 \mathrm{~mm}$. In contrast to this, the average length of the larvae thirty days after the beginning of spring activities under more normal conditions, such as existed on Vancouver Island, was not less than $15 \mathrm{~mm}$. Then in the latter part of July practically the entire brood of caterpillars was found to have re-spun cocoons in which the larvae had again become dormant. These cocoons were from 5 to $6 \mathrm{~mm}$, in length, whereas the primary hibernacula were not over $2 \mathrm{~mm}$. But like the latter the new set of cocoons were formed in sheltered nooks such as between bud scales or between needles which had become matted together. In addition, a favourite place on spruce was in the crevices of abandoned pine-apple galls of the spruce gall aphis.

In 1930 the caterpillars were found to have re-emerged by the middle of June. As the weather during this month was also unfavourable, being not unlike that of June, 1929, the growth of these partly developed larvae was further retarded. However, by the end of July and the first part of August the adult stage was reached and egg laying soon followed. In 1931 the development of the new brood was a repetition of that of 1929 with the cater- 
pillars returning to hibernation in the latter part of July, while still not more than half grown.

Measurements of the head capsules of over 1000 larvae collected at intervals throughout the three seasons showed that whereas there are six instars in the development of spruce budworm larvae, the majority of caterpillars in 1929 and again in 1931 only reached the third or fourth instar before returning to hiberation and that practically all the larvae taken at the beginning of the season in 1930 were already of the fifth instar in contrast to second instar larvae normally present at such times. Additional data obtained indicated that close to 99 per cent of the survivors of the current brood in 1931 returned to hibernation and that not over 1 per cent were able to reach the adult stage the same season.

Since the feeding during the first year of the two year cycle was confined to young larvae the amount of injury to the trees in 1929 and 1931 was relatively light, whereas in 1930, the second year of the cycle, the defoliation was much heavier in that more mature larvae were then present. This variation in the amount of defoliation during the two years has given the infestation the appearance of also being on a two year cycle, a characteristic which has been more or less evident throughout the course of the current Barkerville infestation. Past records show that in 1922, 1924, 1926 and 1928 the infestation was reported to be epidemic, while in the intervening years the outbreak was considered inactive. If the budworm in this district has become definitely established on a two year cycle the persistency of the present infestation can be largely accounted for. Not only does such a characteristic greatly reduce the effects of the climatic conditions as a control factor, but it also, as has been found, tends to minimize the effectiveness of the various parasites.

With the exception of the current Barkerville infestation, the outbreaks of spruce budworm in British Columbia have invariably subsided within three to five years. In no case was the available food supply exhausted, but instead the decline of the outbreaks was brought about by other natural control factors.

Parasites have undoubtedly played an important part in the suppression of the various outbreaks but the studies have shown that in the recent infestations, at least, their effectiveness has been in the combined activities of a number of different species rather than the work of only one or two species.

Three hymenopterous parasites, Phytodietus fumiferanae Rohw., Ephialtes obesus (Cush.) and Epiurus innominatus Vier., unknown in the East, have been identified among the parasitic material recovered. P. fumiferanae proved to be an effective parasite in the infestations in Douglas fir but was not taken in the Barkerville district. E. obesus was found to be generally distributed, 
although not numerous, while $E$. innominatus is of doubtful status, observations indicating that it may possibly be a hyperparasite.

Field observations suggest that birds, ants and spiders are also important control factors in the West, and in the Barkerville district in particular, several as yet undetermined pathological and physiological diseases were effective against the budworm.

Except in the Barkerville district, secondary insects proved of minor importance. However, in this area the balsam bark beetle, Drycoetes confusus Sw., has assumed epidemic form, with the result that over 50 per cent. of the mature balsam on a considerable portion of the budworm infested area have already been killed, and in all probability fully 90 per cent. of such trees will succumb before the bark beetle epidemic has run its course.

In no instance were mature trees found to be killed solely by the work of the budworm. However, the tops of a large number of trees were found to be killed back for a distance varying from only one year's growth up to a distance of several feet, and many of the trees, in the Barkerville district especially, have become decidedly stag-headed as a result of the repeated injury.

The ability of the defoliated trees in the coast region to send out a second growth the same season, immediately following the spruce budworm feeding period, was an important factor in reducing the injury resulting from the budworm outbreaks in that district.

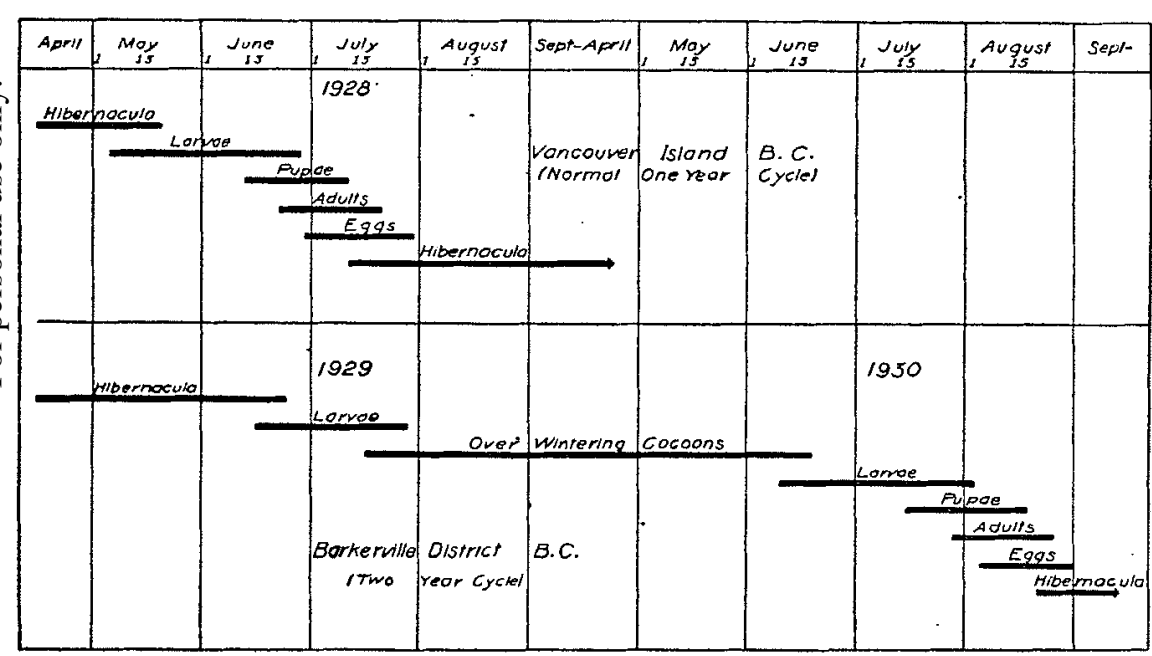

Line Graph Showing Life Cycle of Spruce Budworm 